\title{
Doctor José Carrillo Yáñez: homenaje póstumo a su legado de trabajo colaborativo y conformación de equipos de investigación
}

\author{
Dinazar Escudero-Avila, Eric Flores-Medrano
}

Este 23 de marzo, nuestra comunidad se unió en una voz para escribir mensajes de despedida a nuestro querido amigo, el profesor José Carrillo Yáñez. Su fallecimiento representa una pérdida irreparable para la Educación Matemática.

Pepe Carrillo, como le llamamos todos, familia y amigos, obtuvo la licenciatura en Matemáticas (1981) y el doctorado en Filosofía y Ciencias de la Educación (1996) en la Universidad de Sevilla, España. Se desempeñó como profesor en la Universidad de Huelva, España, donde, en diciembre de 2012, obtuvo la categoría de Catedrático Universitario. Fue presidente de la Sociedad Española de Investigación en Educación Matemática de 2014 a 2017. Dirigió, aproximadamente, 20 trabajos doctorales, 35 de maestría y fue autor de más de 150 publicaciones entre libros, capítulos de libro y artículos de investigación, de los cuales siete fueron publicados en la Revista Educación Matemática. Sus trabajos de investigación comenzaron al explorar, en su tesis doctoral, los modos de resolver problemas y las concepciones del profesorado de matemáticas.

Sus intereses de investigación y su labor en la universidad de formador de maestros de primaria, le orientaron hacia el estudio del conocimiento y desarrollo profesional del profesor de matemáticas. Así, a partir de la década de los 90 se comenzaron a gestar dos grupos académicos liderados por él, y que continúan activos hasta el día de hoy. Por un lado, el Proyecto de Investigación Colaborativa, conformado mayoritariamente por maestros y maestras de educación 
básica, el cual ha tenido la intención de construir, en comunidad, respuestas a los problemas profesionales detectados en su día a día. Por otro lado, en el seno del Seminario de Investigación en Didáctica de las Matemáticas (SIDM), se conformó un grupo de estudiantes de máster y doctorado, profesores e investigadores cuyo objetivo fue lograr la comprensión de los distintos fenómenos relacionados con la labor del profesor de matemáticas.

Estos espacios construidos, gestionados e impulsados por Pepe, redituaron en la conformación de la Red Iberoamericana sobre el Conocimiento Especializado del Profesor de Matemáticas, la cual tiene presencia en distintas universidades de 12 países y es reconocida ante la Asociación Universitaria Iberoamericana de Postgrado.

De entre las distintas cualidades que caracterizaban a este gran investigador podemos destacar su simpatía, carisma y cordialidad con todos aquellos que se acercaban a él, a su grupo de investigación y a su espacio de trabajo. Pero, sobre todo, es de resaltar su disposición al diálogo y la búsqueda continua de puntos en común, lo cual, sin duda, ayudó al desarrollo de la Educación Matemática. En este sentido, no era poco común que las personas se acercaran a Pepe en busca de apoyo académico, puesto que él tenía siempre una opinión acertada, un consejo valioso o una crítica constructiva, que sus colegas apreciaban.

A principios de 2012, un grupo de estudiantes de doctorado, con ideas germinales, planteó, en reuniones del SIDM, una serie de cuestionamientos a trabajos propios y ajenos al grupo. El liderazgo y visión de Pepe y la armonía de trabajo entre quienes éramos sus colaboradores, permitieron realizar una dura crítica interna y comenzar con el desarrollo de un nuevo modelo de conocimiento profesional, el Mathematics Teacher's Specialised Knowledge (MTSK). Este fue un momento de florecimiento para su grupo de investigación, no solo por la creación del modelo en sí, sino por la motivación que Pepe imprimía para exponer este trabajo al escrutinio de importantes investigadores y grupos de investigación que pudieran leer y criticar el modelo en espacios como el PME, ICME, CERME, RELME, CIBEM, etcétera, con personas como Fay Turner, Mark Thames, Tim Rowland, Heather Hill, Jeremy Kilpatrick, Alain Kuzniak, Juan D. Godino, Lourdes Figueiras, entre muchos otros. A Pepe le interesaba que el trabajo que se generaba en el grupo se debatiera a partir de miradas objetivas que pudieran ayudar a conformar un producto sólido y útil para la formación y el desarrollo profesional. Hoy, el MTSK ha rebasado el uso exclusivo por parte de nuestro grupo y se encuentra en un acelerado crecimiento. 
Esta misma capacidad para entablar diálogos permitió que la influencia académica de Pepe no se limitara a la alta especialización en un modelo. Gracias a sus gestiones, se logró el establecimiento de trabajos conjuntos con otros modelos analíticos y perspectivas teóricas, entre los cuales podemos destacar las colaboraciones con el grupo que investiga sobre Espacios de Trabajo Matemático.

Además, Pepe realizó diversas codirecciones de tesis en Didáctica de las Ciencias Experimentales. Esto ha permitido el surgimiento de modelos basados en el MTSK que pretenden analizar el conocimiento especializado de los profesores de física, biología, química, estadística, ingeniería eléctrica, lengua castellana y portuguesa.

Aunque extrañaremos, entre muchas otras cosas, sus consejos, su sentido del humor, sus preguntas incisivas y comentarios inteligentes, nos queda una larga agenda de trabajo que Pepe estableció y cuyo cumplimiento, esperamos nos acerque a hacer justicia al arduo trabajo que él realizó por la Educación Matemática. Y es que, ante la pregunta de Joan Manuel Serrat "¿quién pondrá fin a mi diario al caer la última hoja de mi calendario?", estamos convencidos de que a ese final del diario de Pepe le quedan muchas horas de discusión y que devendrá en múltiples tesis, artículos y programas de formación, continuados por quienes orgullosamente, nos llamamos a nosotros mismos el grupo de Pepe Carrillo.

Quienes escribimos este homenaje nos sentimos halagados con esta oportunidad, pero, a la vez, con una enorme responsabilidad de tratar de representar el sentir de una gran comunidad que conforma su grupo de investigación. Esperamos que nuestras palabras vertidas en este espacio sirvan para transmitir a Inma, Daniel, Samuel y Alejandro la gran admiración y agradecimiento que una comunidad entera siente por Pepe como profesor, investigador, colega y amigo. Deseamos que este sentido homenaje les reconforte. 